Bài báo khoa học

\title{
Ú̉ng dụng đồng hóa dữ liệu dự báo các trường khí tượng độ phân giải cao cho khu vực Than Uyên (Lai Châu)
}

\author{
Nguyễn Đức Nam ${ }^{1}$, Nguyễn Tiến Mạnh ${ }^{1}$, Nguyễn Xuân Anh ${ }^{1}$, Phạm Lê Khương1,3, \\ Nguyễn Thanh Linh ${ }^{1}$, Nguyễn Văn Hiệp ${ }^{1,2^{*}}$
}

${ }^{1}$ Viện Vật lý Địa cầu; ducnam.mi@gmail.com; ntmanh18196@gmail.com; anhnx@igpvast.vn; khuongpl@igp-vast.vn; nguyenthanhlinht58@gmail.com

${ }^{2}$ Đài KTTV khu vực đồng bằng Bắc Bộ; hiepwork@gmail.com

${ }^{3}$ Học viện Khoa học và Công nghệ; khuongpl@igp-vast.vn

*Tác giả liên hệ: hiepwork@gmail.com; Tel.: +84-963297457

Ban Biên tập nhận bài: 15/1/2021; Ngày phản biện xong: 22/3/2021; Ngày đăng bài: $25 / 4 / 2021$

Tóm tắt: Nghiên cứu này sử dụng mô hình WRF để dự báo các trường khí tượng độ phân giải cao cho khu vực có địa hình phức tạp tại Than Uyên (Lai Châu). Nghiên cứu ứng dụng phương pháp đồng hóa dữ liệu 3DVAR nhằm bổ sung số liệu quan trắc nâng cao chất lượng điều kiện ban đầu của mô hình. Số liệu được sử dụng để chạy chương trình đồng hóa 3DVAR bao gồm số liệu gió vệ tinh, số liệu quan trắc tại trạm và số liệu quan trắc cao không ở phạm vi miền tính của mô hình. Kết quả cho thấy đồng hóa số liệu đã cải thiện chất lượng dự báo nhiệt độ, độ ẩm và lượng mưa, diện mưa so với trường hợp không đồng hóa.

Tù̀ khóa: WRF3DVAR; Đồng hóa số liệu; Spin-up; Mưa lớn.

\section{Mở đầu}

Dự báo thời tiết là một trong những nhiệm vụ quan trọng của ngành Khí tượng, có vai trò không nhỏ đối với các ngành, các lĩnh vực khác nhau trong đời sống xã hội. Trong những năm gần đây, khí hậu toàn cầu đã và đang biến đổi mạnh mẽ, các hiện tượng thời tiết cực đoan ngày càng có dấu hiệu gia tăng trên thế giới cũng như ở Việt Nam. Năm 2020 các tỉnh Bắc Bộ không chỉ chịu những thiệt hại to lớn do rét đậm, rét hại, mưa đá gây ra mà còn hứng chịu ảnh hưởng của những đợt mưa lớn. Theo báo cáo của Văn phòng thường trực Ban Chỉ huy Phòng chống thiên tai và Tìm kiếm cứu nạn tỉnh Lai Châu, từ $19 \mathrm{~h}$ ngày $11 / 7$ đến $13 \mathrm{~h}$ ngày 12/7 khu vực Lai Châu đã có mưa với lượng mưa phổ biến từ 30-100 mm, riêng tại thị trấn Tân Uyên 198 mm, Nậm Sỏ 144 mm, Khun Há 133 mm, Bình Lư 124 m, Mường Mít $101 \mathrm{~mm}$. Mưa kéo dài kéo theo lũ quét, sạt lở đất đã gây một số thiệt hại về tài sản của Nhà nước và nhân dân. Việc dự báo chính xác hiện tượng mưa lớn sẽ góp phần giảm thiểu những thiệt hại mà nó gây ra. Trong bài báo này, nhóm nghiên cứu tiến hành thử nghiệm dự báo các trường khí tượng độ phân giải cao trong đợt mưa lớn tháng 7 năm 2020 tại khu vực Lai Châu bằng ứng dụng kĩ thuật đồng hóa số liệu.

Nam Trung Quốc là khu vực có cơ chế mưa gần với Việt Nam, nên những năm gần đây có nhiều nghiên cứu về dự báo mưa khu vực gần biên giới Việt Nam. Trong "Cơ chế lượng mưa kỷ lục đột biến ở Quảng Châu (Trung Quốc)" [1], tác giả đã nghiên cứu các yếu tố gây ra lượng mưa lớn, bao gồm các hình thế thời tiết, hiệu ứng địa hình và hiệu ứng đô thị bằng mô hình WRF. Nghiên cứu cho thấy rằng luồng không khí nóng ẩm ở Biển Đông liên tục cung cấp điều kiện thuận lợi cho sự phát triển mưa lớn. Mưa tạo ra một vùng lạnh yếu kết hợp với dòng đối lưu đã góp phần hình thành liên tục những ổ dông mới. Sự tương tác giữa 
luồng không khí lạnh và luồng không khí nóng, ẩm kết hợp với đối lưu tầng thấp tạo thành một hệ thống mưa đối lưu liên tục. Trong nghiên cứu khác, tác giả đã điều tra đặc điểm và cơ chế mưa và gió trong ngày gần bờ biển phía Nam Trung Quốc sử dụng số liệu vệ tinh, dữ liệu mô hình WRF [2]. Kết quả nghiên cứu cho thấy, chu kỳ lượng mưa chia thành 2 khu vực trên bờ và ngoài khơi, chu kỳ gió (thẳng đứng) hàng ngày cũng tương tự như lượng mưa. Sự đối lưu đóng vai trò quan trọng trong chu kỳ ngày của lượng mưa cũng quyết định chu kỳ gió. Các dự báo dị thường lượng mưa mùa hè Trung Quốc năm 1998 sử dụng mô hình WRF và CCSM4 [3] chỉ ra rằng, mô hình WRF cải thiện mô phỏng lượng mưa, các sai số hệ thống ở phía đông cao nguyên Tây Tạng đã được loại bỏ, tuy nhiên ở vùng Hoa Bắc và Đông Bắc (Trung Quốc) các sai số còn tồn tại. Mô hình WRF cải thiện dự báo lượng mưa trong mùa hè, đặc biệt phía Nam lưu vực sông Dương Tử và Nam Trung Quốc, nhưng chưa cải thiện tốt ở Bắc và Đông Bắc Trung Quốc. Ngoài ra, mô hình WRF cho lượng mưa trung bình mùa, khung thời gian theo mùa, dự báo mưa Mei-yu gần quan trắc và tốt hơn CCSM (mô hình hệ thống khí hậu cộng đồng), nhờ có độ phân giải địa hình tốt của mô hình WRF.

Tại Việt Nam, mô hình dự báo thời tiết khu vực cũng đã được ứng dụng rộng rãi trong nghiên cứu và dự báo nghiệp vụ. Trong nghiên cứu "Đánh giá chất lượng dự báo mưa từ mô hình số trị cho khu vực Hà Nam và Nam Định trong năm 2019" nhóm tác giả đã cho thấy mô hình dự báo không quá thiên cao đối với những ngưỡng mưa nhỏ và thiên thấp đối với những ngưỡng mưa lớn như mô hình toàn cầu [4]. Trong một nghiên cứu khác, mô hình WRF mô phỏng đợt mưa lớn từ ngày $01-06 / 8 / 2017$ ở tỉnh Sơn La đã cho thấy, diện mưa và lượng mưa mô phỏng thường cao hơn với quan trắc. Mô hình đã nắm bắt được phần nào phân bố không gian và diễn biến thời gian của mưa trên khu vực [5]. Sử dụng lưới lồng và hai sơ đồ đối lưu khác nhau để dự báo mưa lớn Trung Bộ từ 1 đến 3 ngày một tác giả đã chỉ ra rằng, vùng mưa dự báo có xu hướng lệch với mưa thực tế và lượng mưa thường thấp hơn so với thực tế [6].

Để nâng cao chất lượng dự báo mưa lớn, có nhiều phương pháp đã được sử dụng, trong đó có kĩ thuật đồng hóa số liệu. Sử dụng mô hình WRF kết hợp với số liệu địa phương để dự báo mưa lớn do không khí lạnh kết hợp với dải hội tụ nhiệt đới từ 1 đến 3 ngày cho khu vực Trung Trung Bộ cho thấy, ở hầu hết các trạm, lượng mưa dự báo trong trường hợp có cập nhật số liệu địa phương cho kết quả tốt hơn không cập nhật số liệu địa phương [7]. Sử dụng đồng hóa số liệu quan trắc truyền thống và số liệu thám sát thẳng đứng từ vệ tinh cực NOAA cho mô hình WRFARW dự báo 10 đợt mưa lớn điển hình trong 3 năm (2010-2012) cho thấy, việc đưa vào đồng hóa số liệu truyền thống và phi truyền thống đã giảm được sai số mô hình một cách rõ rệt, đồng thời làm tăng khả năng phát hiện mưa lớn [8]. Đồng hóa số liệu vệ tinh MODIS để dự báo mưa lớn ở khu vực Trung Bộ trong hai mùa mưa 2007, 2008 bằng mô hình WRF cho thấy đồng hóa số liệu MODIS đã cải thiện được đáng kể chất lượng dự báo cả diện mưa và lượng mưa trong $30 \mathrm{~h}$ đầu dự báo [9]. Đồng hóa số liệu profile nhiệt độ và nhiệt độ điểm sương từ vệ tinh MODIS thông qua sơ đồ đồng hóa 3DVAR đã cải thiện được dự báo cả về tâm mưa và lượng mưa, đặc biệt trong hạn dự báo 30h [10]. Phương pháp 4DVAR được thử nghiệm thông qua mô hình WRF dự báo mưa lớn ở khu vực Nam Bộ cho thấy sai số dự báo được cải thiện ở cả hạn dự báo $12 \mathrm{~h}$ và $24 \mathrm{~h}$, đồng thời sai số nhỏ hơn trường hợp mặc định ở các ngưỡng mưa nhỏ dưới $30 \mathrm{~mm}$ và mưa lớn trên $70 \mathrm{~mm}$ [11]. Sử dụng phương pháp 3DVAR đồng hóa số liệu radar cho mô hình WRF dự báo mưa lớn khu vực Thành phố Hồ Chí Minh cho thấy đồng hóa với chế độ warm start cho mô phỏng mưa lớn tốt hơn khá nhiều với chế độ cold start [12]. Đồng hóa các loại số liệu cho mô hình WRF dự báo mưa lớn cho khu vực Tây Nguyên do ảnh hưởng của bão Damrey (2017) bằng hệ thống đồng hóa dữ liệu dạng điểm GSI cũng cho thấy chất lượng dự báo về diện và lượng mưa ở hạn dự báo 24 giờ đã được cải thiện đáng kể [13].

\section{Phương pháp và số liệu}

\section{1. Đồng hóa WRF 3D-Var}


Mô hình dự báo và nghiên cứu thời tiết (ARW-WRF) phiên bản 4.0.1 được sử dụng trong nghiên cứu này là mô hình khí tượng phi thủy tĩnh. Đồng hóa dữ liệu WRF-3Dvar là một hệ thống đồng hóa số liệu được phát triển cho mô hình WRF. Hệ thống WRF-3DVAR được phát triển bởi [14] với việc sử dụng công thức biến phân tăng [15]. Nhìn chung mục đích chính của hệ thống đồng hóa số liệu WRF-3DVAR là tạo một trường điều kiện ban đầu tốt hơn cho mô hình WRF thông qua việc tính lặp hàm giá [16]:

$$
J(x)=\frac{1}{2}\left(x-x^{b}\right)^{T} B^{-1}\left(x-x^{b}\right)+\frac{1}{2}\left[H(x)-y^{0}\right]^{T} O^{-1}\left[H(x)-y^{0}\right]
$$

Trong đó $\mathrm{B}$ là ma trận sai số trường nền; $\mathrm{O}$ là ma trận sai số quan trắc; $\mathrm{H}(\mathrm{x})$ là toán tử quan trắc, $\mathrm{X}$ là vector trạng thái khí quyển; $\mathrm{Y}$ là quan trắc.

Hiệu quả của đồng hóa biến phân ba chiều phụ thuộc vào thống kê sai số trường nền (Background error statistics-BES) vì nó chứa thông tin về sự lan truyền của các giá trị số liệu quan trắc trong không gian của mô hình và cũng xác định được cân bằng về vật lý [17] Phương pháp tính sai số trường nền NMC (National Meteorological Centre) [18] là một trong những phương pháp được sử dụng phổ biến nhất để tính toán sai số trường nền theo miền tính cụ thể. Phương pháp NMC xấp xỉ cấu trúc của ma trận $\mathrm{B}$ thông qua sự khác biệt thống kê giữa các hạn dự báo 24 giờ và 12 giờ từ mô hình khu vực. Nghiên cứu này sử dụng phương pháp NMC để tính sai số trường nền với thời gian tính từ ngày 01 tháng 07 đến ngày 31 tháng 07 năm 2020.

\subsection{Số liệu}

Điều kiện đầu vào và điều kiện biên sử dụng số liệu dự báo GFS của NCEP/NCAR (NCEP-The National Center for Environmental Prediction /NCAR-The National Center for Atmospheric Research) có độ phân giải ngang là $0,5 \times 0,5$ độ kinh vĩ và định dạng grib2 (https://www.ncdc.noaa.gov/data-access/model-data/model-atasets/global-forcastsystem-gfs). Các số liệu được sử dụng để đồng hóa bao gồm số liệu gió vệ tinh, số liệu quan trắc bề mặt và cao không. Số liệu gió vệ tinh được lấy ở khu vực Ấn Độ, Tây Bắc Thái Bình Dương và được downloads từ trang website http://tropic.ssec.wisc.edu với định dạng ASCII. Số liệu quan trắc bề mặt và cao không được lấy từ các trạm khí tượng bề mặt và cao không khu vực Việt Nam và lân cận thuộc miền tính của mô hình. Số liệu này được khai thác thông qua website http://weather.uwyo.edu. Các số liệu trên đều được xử lý đưa về định dạng litterr để chạy chương trình obsproc nhằm kiểm tra chất lượng và loại bỏ các số liệu không thuộc miền tính của mô hình.

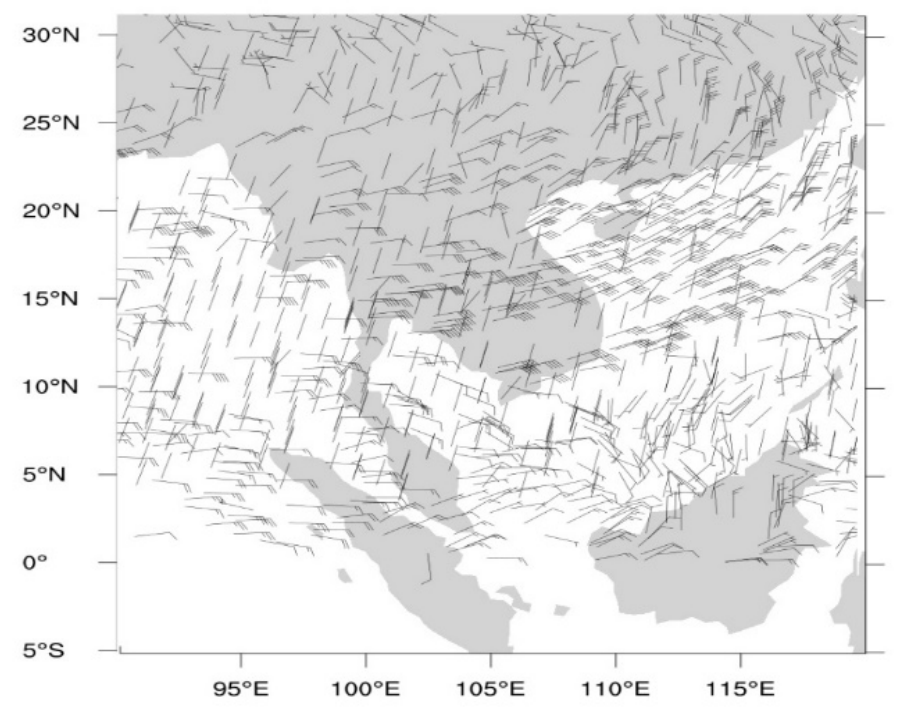

Hình 1. Số liệu gió vệ tinh các mực độ cao sử dụng trong nghiên cứu. 
Số liệu quan trắc tại trạm được sử dụng để đánh giá các trường khí tượng dự báo. Số liệu mưa vệ tinh Gsmap được sử dụng để so sánh đánh giá với trường mưa của mô hình. Số liệu mưa vệ tinh Gsmap được sử dụng có độ phân giải là $0,1 \times 0,1$ độ kinh vĩ (https://sharaku.eorc.jaxa.jp/GSMaP).

\subsection{Thiết kế thí nghiệm}

Trong nghiên cứu này chúng tôi sử dụng mô hình WRF và WRFDA phiên bản V4.0.1 với ba lưới lồng tương tác hai chiều, độ phân giải tương ứng là: $27 \mathrm{~km}, 9 \mathrm{~km}, 3 \mathrm{~km}, 1 \mathrm{~km}$ (Hình 2). Số điểm lưới tương ứng là $174 \times 156 ; 232 \times 259 ; 220 \times 214$ và $121 \times 136$ điểm lưới với 38 mực thẳng đứng.

Miền 1 được thiết kế đủ rộng để mô hình có thể nắm bắt được các quá trình hoàn lưu quy mô lớn ảnh hưởng đến khu vực Việt Nam, miền nhỏ được thu hẹp phạm vi bao trọn khu vực Tây Bắc Bộ.

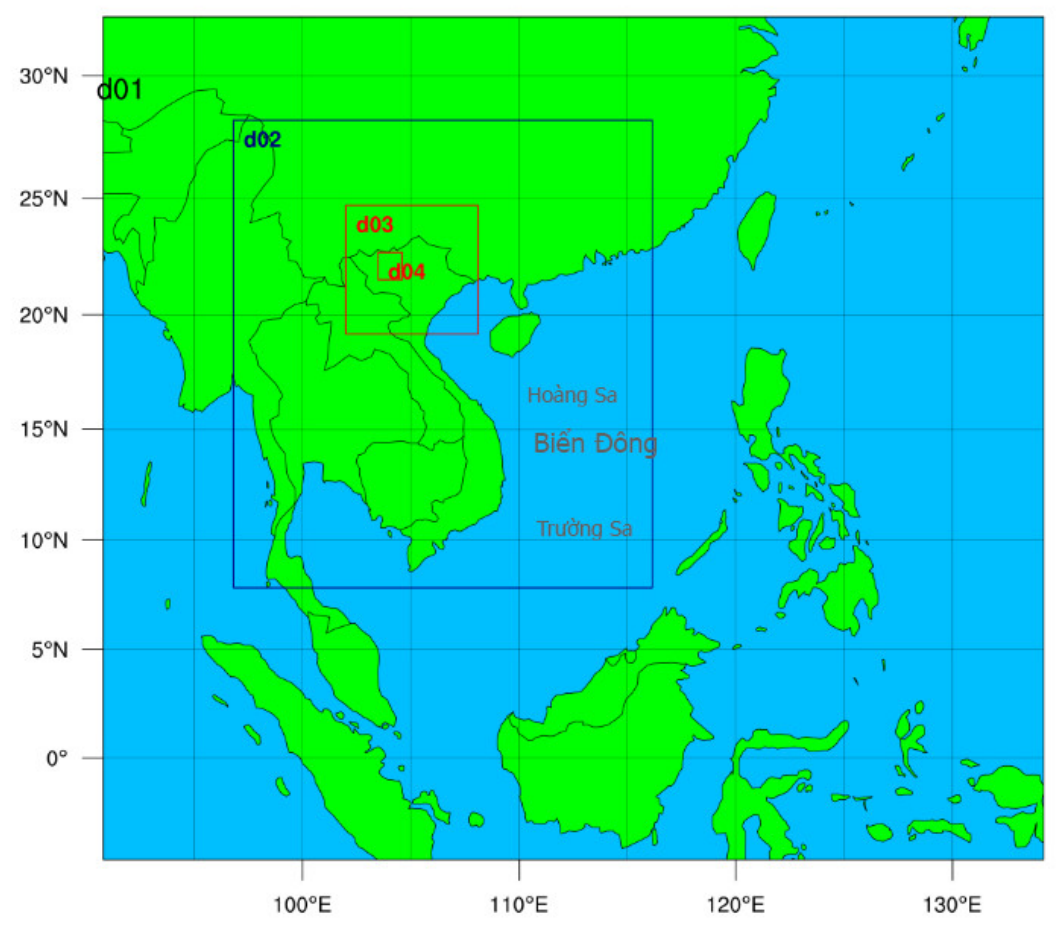

Hình 2. Các miền tính của mô hình.

Bộ tham số vật lý của mô hình WRF được lựa chọn để mô phỏng các trường khí tượng khu vực Than Uyên, Lai Châu được thể hiện qua Bảng 1.

Bảng 1. Sơ đồ vật lý sử dụng trong thí nghiệm.

\begin{tabular}{|c|c|c|}
\hline STT & Tham số mô hình & Tham số lựa chọn \\
\hline 1 & Sơ đồ vi vật lý mây & $\begin{array}{c}\text { Thompson } \\
\text { WSM 6-class }\end{array}$ \\
\hline 2 & Tham số hóa đối lưu & $\begin{array}{c}\text { Betts-Miller-Janjic } \\
\text { Kain-Fritsch }\end{array}$ \\
\hline 3 & Bức xạ sóng ngắn & rrtmg scheme \\
\hline 4 & Bức xạ sóng dài & rrtmg scheme \\
\hline 5 & Lớp biên hành tinh & YSU scheme \\
\hline
\end{tabular}

Nghiên cứu thực hiện thử nghiệm dự báo đợt mưa từ ngày 10 đến 13 tháng 07 năm 2020 . Thời điểm ban đầu của mô hình từ $00 \mathrm{z}$ ngày 10 tháng 07 năm 2020, dự báo hạn 72 giờ tới thời điểm $00 \mathrm{z}$ ngày 13 tháng 7 năm 2020. 


\subsection{Phuơng pháp đánh giá}

Nghiên cứu sử dụng giản đồ Taylor để so sánh đánh giá. Giải đồ Taylor được phát minh, được dùng để định lượng sai số giữa giá trị dự báo và giá trị quan trắc theo ba chỉ số thống kê: Hệ số tương quan, sai số bình phương trung bình (RMSE) và độ lệch chuẩn. Giải đồ Taylor có thể được xây dựng với các phần mềm như R, GrADS, IDL, MATLAB, NCL, Python, ... Trong báo cáo này sử dụng phần mềm tính toán thống kê $\mathrm{R}$ để tính toán và vẽ giải đồ Taylor.

Hệ số tương quan giữa chuỗi $\mathrm{X}$ và $\mathrm{Y}$ với $\mathrm{n}$ cặp giá trị $\mathrm{x}$ và $\mathrm{y}$ được tính theo công thức sau:

$$
r_{x y}=\frac{\sum_{i=1}^{n}\left(x_{i}-\bar{x}\right)\left(y_{i}-\bar{y}\right)}{\sqrt{\sum_{i=1}^{n}\left(x_{i}-\bar{x}\right)^{2} \sum_{i=1}^{n}\left(y_{i}-\bar{y}\right)^{2}}}
$$

Trong đó: $\bar{x}=\frac{1}{n} \sum_{i=1}^{n} x_{i}$ và $\bar{y}=\frac{1}{n} \sum_{i=1}^{n} y_{i}$

$r_{x y}$ gọi là hệ số tương quan mẫu của $\mathrm{X}$ và $\mathrm{Y}$. Hệ số tương quan nhận giá trị trên đoạn $[-1 ; 1]$. Nếu hệ số tương quan $(\mathrm{r})$ dương cho biết $\mathrm{X}$ và $\mathrm{Y}$ biến động cùng chiều và âm thì ngược lại.

Trong các công thức dưới đây, Fi và Oi tương ứng là giá trị mô hình và giá trị quan trắc của một biến nào đó $\mathrm{i}=1,2, \ldots, \mathrm{N}, \mathrm{N}$ là dung lượng mẫu.

Sai số bình phương trung bình (Root Mean Squared Error-RMSE):

$$
R M S E=\sqrt{\frac{1}{n} \sum_{i=1}^{n}\left(F_{i}-O_{i}\right)^{2}}
$$

Dựa vào độ lệch chuẩn chúng ta biết được độ phân tán của tổng thể. Độ lệch chuẩn là căn bậc 2 của phương sai được tính như công thức dưới đây:

$$
\sigma=\sqrt{\frac{\sum_{\mathrm{i}=1}^{\mathrm{n}}\left(\mathrm{x}_{\mathrm{i}}-\overline{\mathrm{x}}\right)^{2}}{\mathrm{n}}}
$$

\section{Kết quả và thảo luận}

\subsection{Kết quả lựa chọn tham số vật lý}

Trong nghiên cứu này, để dự báo mưa lớn ở khu vực Lai Châu từ ngày 10-13/7/2020 các sơ đồ tham số đối lưu và vi vật lý mây trong mô hình được lựa chọn kế thừa từ các nghiên cứu trong nước, là các sơ đồ vốn được sử dụng rộng rãi [19-22], đó là: sơ đồ đối lưu KainFritsch (kí hiệu 1) và Betts-Miller-Janjic (BMJ) (kí hiệu 2); sơ đồ tham số hóa vi vật lý mây Thompson (kí hiệu 8) và WSM 6-class (kí hiệu 6).

Kết quả thử nghiệm được hiển thị, so sánh với bản đồ ước lượng mưa vệ tinh độ phân giả 0.1 độ của GSMAP (Hình 3).

Phân tích bản đồ lượng mưa tích lũy 24 giờ (Hình 3), có thể nhận thấy cả 4 trường hợp thử nghiệm mô hình đều nắm bắt được mưa ở khu vực Lai Châu, tuy nhiên kết quả trường hợp $4(\mathrm{Cu}=2, \mathrm{MP}=8)$ cho kết quả diện mưa phù hợp với số liệu GSMAP hơn. Ngoài ra, mô hình còn mô phỏng được mưa ở một số địa điểm lân cận như Yên Bái, Sơn La và vùng núi dọc biên giới Việt Trung thuộc khu Đông Bắc như Hà Giang, Cao Bằng. Trên cơ sở đó, nghiên cứu sẽ lựa chọn sử dụng bộ tham số gồm sơ đồ tham số hóa đối lưu BMJ (2) và sơ đồ vi vật lý Thompson (8) để thực hiện đồng hóa số liệu gió vệ tinh, số liệu trạm và số liệu cao không nhằm dự báo các trường khí tượng độ phân giải cao cho khu vực Lai Châu. 


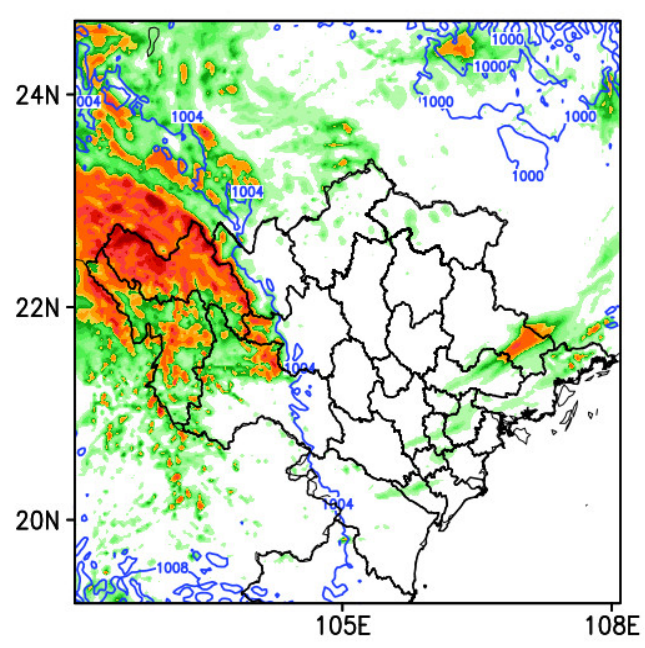

a)

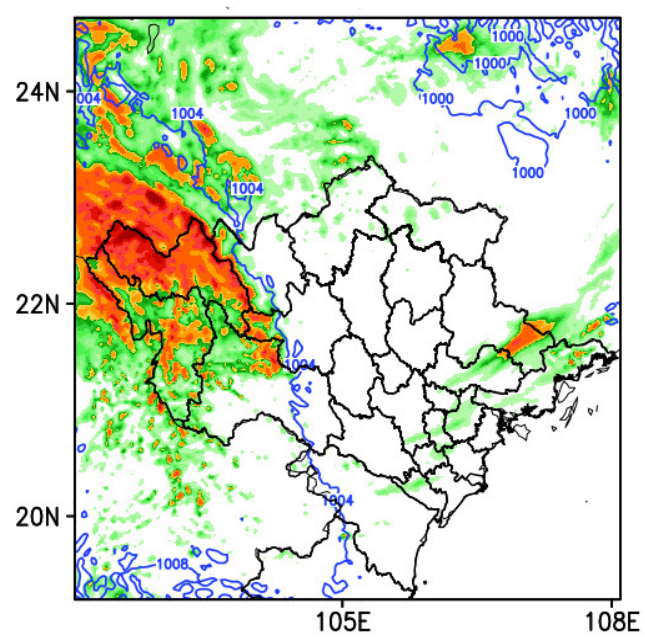

C)

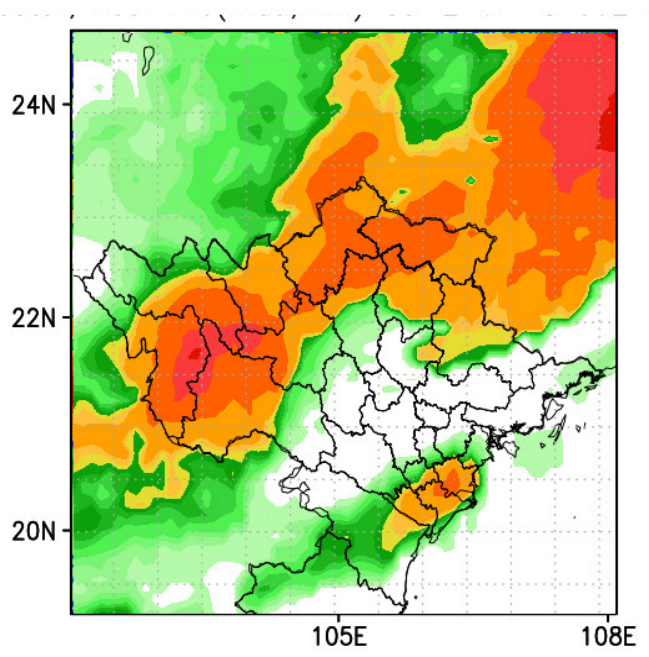

e)

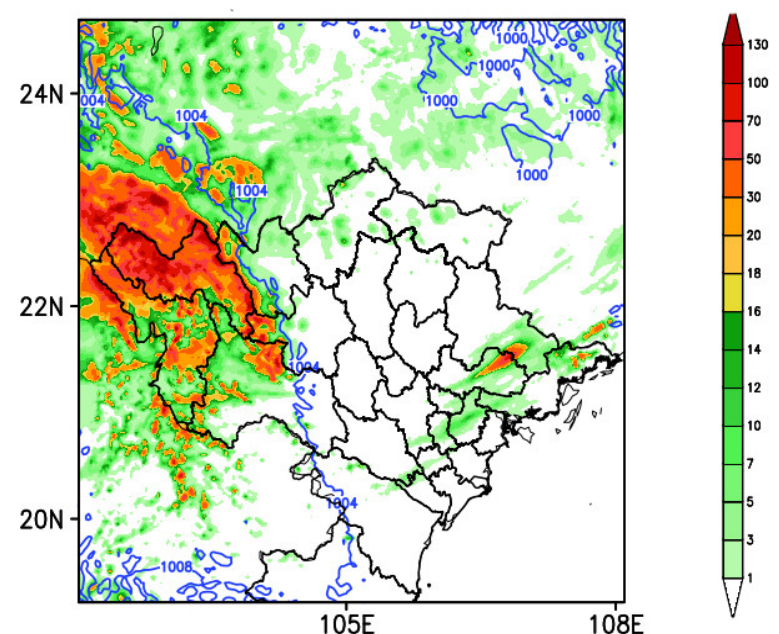

b)

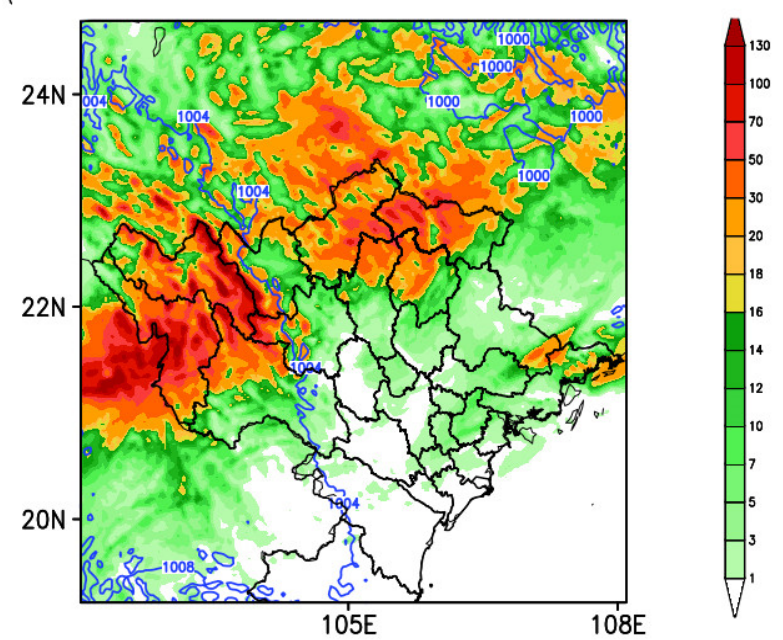

d)

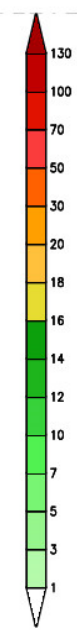

Hình 3. Bản đồ lượng mưa tích lũy hạn 24 h tính từ $00 \mathrm{Z}$ ngày $10 / 7 / 2020$ đến $00 \mathrm{Z}$ ngày $11 / 7 / 2020$ các trường hợp: $\mathrm{a})$ : $\mathrm{Cu}=1, \mathrm{MP}=6 ; \mathrm{b}): \mathrm{Cu}=2, \mathrm{MP}=6 ; \mathrm{c}): \mathrm{Cu}=1, \mathrm{MP}=8 ; \mathrm{d}$ ): $\mathrm{Cu}=2, \mathrm{MP}=8$ và bản đồ GSMAP (e). 


\subsection{Kết quả dụ báo tù ngày 10-13/07/2020}

Dưới đây là kết quả đồng hóa các số liệu gió vệ tinh, số liệu quan trắc tại trạm và số liệu cao không tại thời điểm 00z ngày 10 tháng 07 năm 2020 (Hình 4).
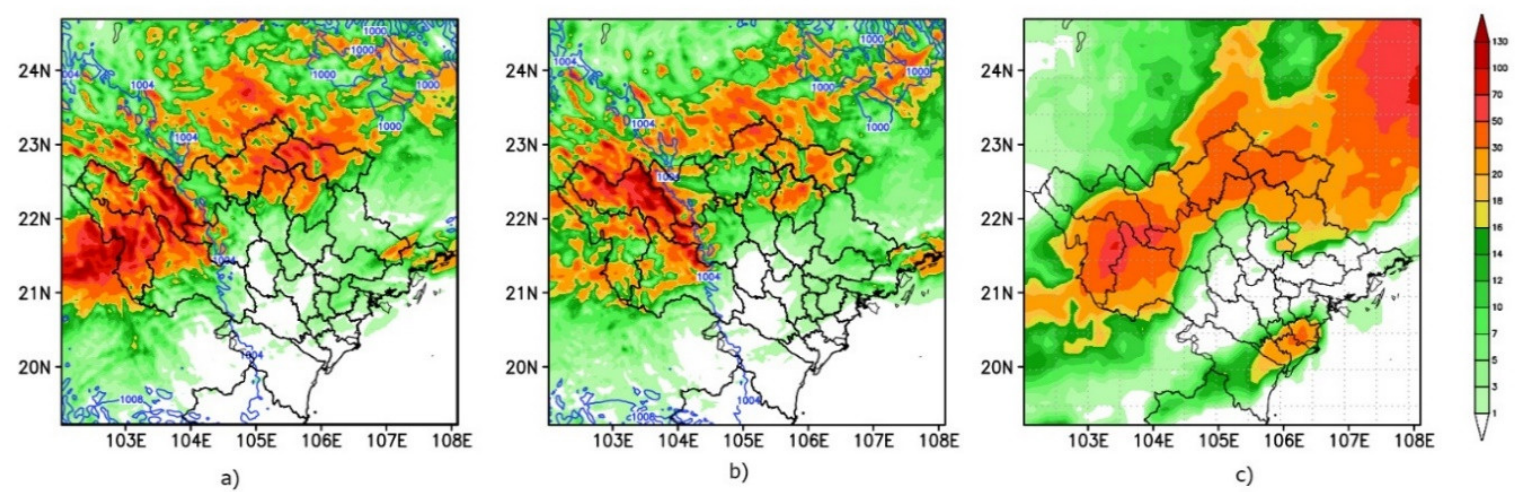

Hình 4. Bản đồ lượng mưa tích lũy miền d03 hạn 24 h tính từ $00 \mathrm{Z}$ ngày $10 / 7 / 2020$ đến $00 \mathrm{Z}$ ngày 11/7/2020 tại các trường hợp: a) Không đồng hóa số liệu. b) Có đồng hóa số liệu. c) Số liệu mưa GSMAP.

So sánh kết quả mô phỏng với số liệu mưa vệ tinh GSMAP (Hình 4) cho thấy, trường hợp có đồng hóa số liệu đã mô phỏng được vùng mưa phù hợp hơn so với trường hợp không có đồng hóa. Cụ thể, trường hợp đồng hóa số liệu đã loại bỏ được vùng mưa ở khu vực giáp ranh giữa Lào và tỉnh Điện Biên, nơi mà trường hợp không đồng hóa số liệu cho mưa lớn. Tại khu vực Than Uyên (Lai Châu) đồng hóa số liệu cũng cải thiện đáng kể chất lượng dự báo lượng mưa.
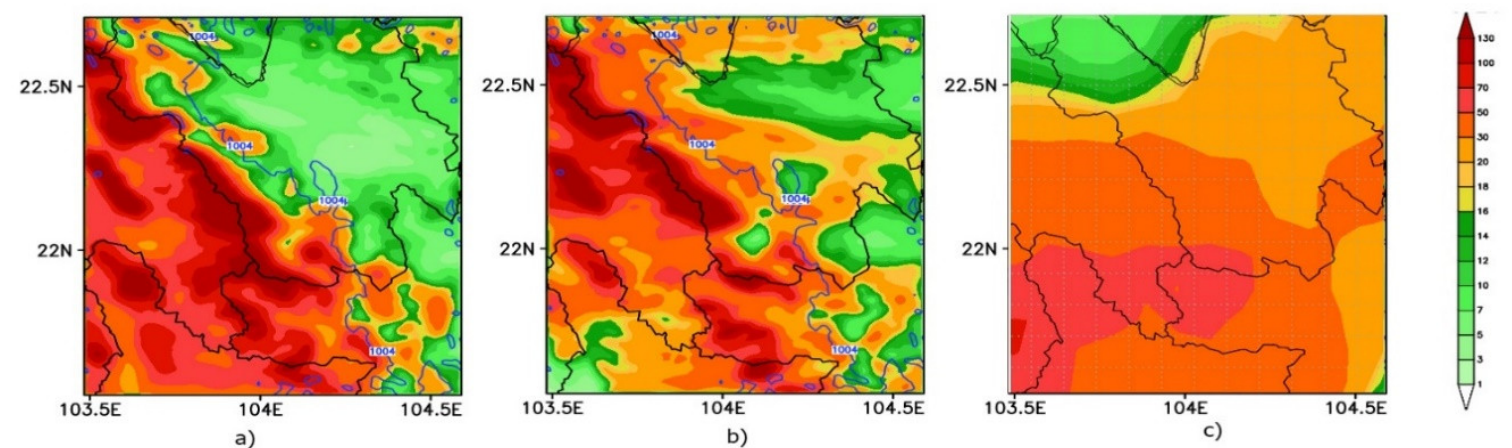

Hình 5. Bản đồ lượng mưa tích lũy miền d04 hạn 24 h tính từ $00 \mathrm{Z}$ ngày 10/7/2020 đến $00 \mathrm{Z}$ ngày 11/7/2020 tại các trường hợp: a) Không đồng hóa số liệu. b) Có đồng hóa số liệu. c) Số liệu mưa GSMAP.

Phân tích bản đồ trường nhiệt độ không khí tại độ cao $2 \mathrm{~m}$ ở thời điểm $00 \mathrm{Z}$ ngày 11/7/2020 của miền tính 3 (Hình 6) có thể thấy được một cách tổng quát nhiệt độ không khí trường hợp có đồng hóa số liệu cao hơn trường hợp mặc định từ 1-2 độ $\mathrm{C}$, đặc điểm này dễ dàng nhận thấy tại khu vực Tây Bắc và phía tây và tây nam Đồng bằng Bắc Bộ. Ở trường hợp mặc định, nhiệt độ không khí dao động từ 18 đến dưới 24 độ $\mathrm{C}$, tuy nhiên nhiệt độ phổ biến ở mức dưới 22 độ $\mathrm{C}$, trừ khu vực phía bắc và phía đông tỉnh Sơn La. Ở trường hợp có đồng hóa số liệu, nền nhiệt trung bình phổ biến ở khoảng 20-24 độ C, có nơi trên 24 độ C trong khi trường hợp không đồng hóa, diện tích khu vực có nhiệt độ từ 22-24 độ $\mathrm{C}$ lớn hơn đáng kể.

Hình 7 thể hiện trường gió dự báo của mô hình trường hợp có đồng hóa và không có đồng hóa số liệu. So với mặc định, sau khi đồng hóa số liệu tốc độ gió đã giảm hơn, các vùng 
gió mạnh cũng thu hẹp hơn. Tuy nhiên hướng gió tại mực 10m ở hạn dự báo 24h không có sự khác biệt đáng kể giữa trường hợp có đồng hóa và không đồng hóa.

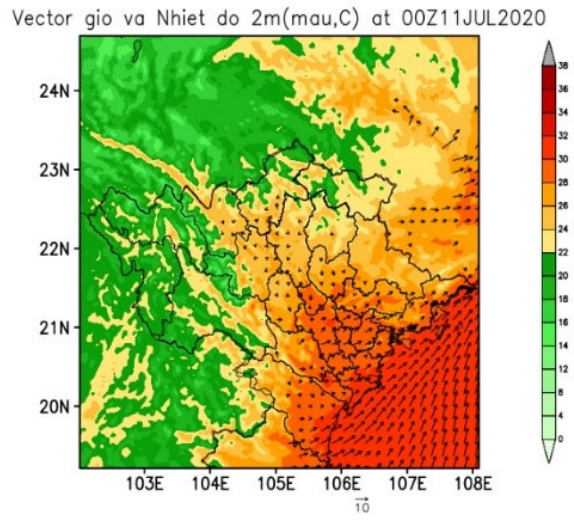

Vector gio va Nhiet do $2 \mathrm{~m}$ (mau,C) at 00Z11JUL2020

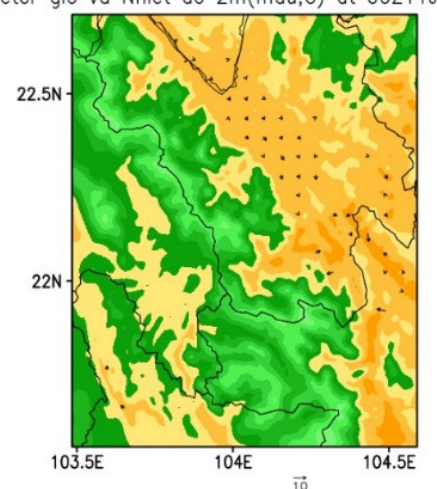

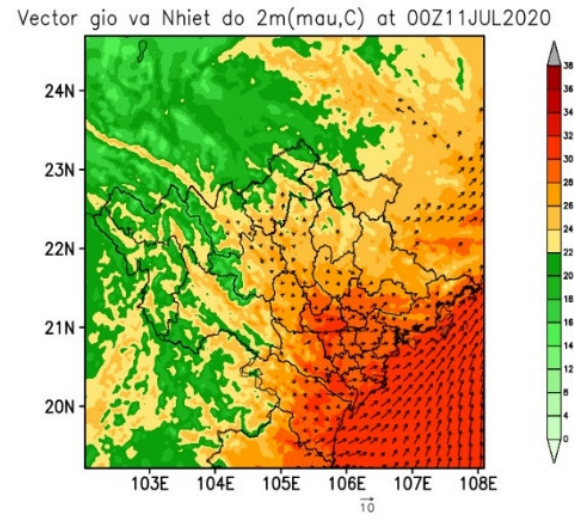

Vector gio va Nhiet do $2 \mathrm{~m}(\mathrm{mau}, \mathrm{C})$ at 00Z11JUL2020

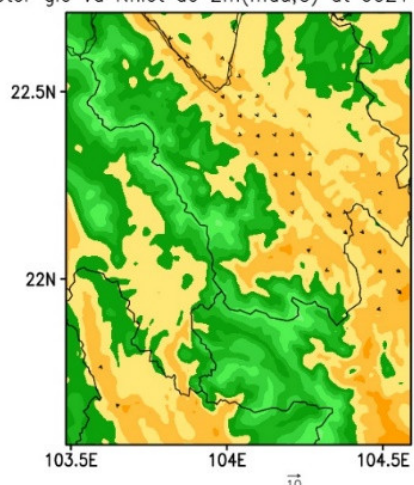

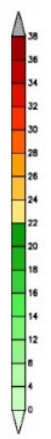

Hình 6. Bản đồ trường nhiệt độ tại độ cao $2 \mathrm{~m}$ và vector gió tại hạn dự báo 24 giờ thời điểm $00 \mathrm{Z}$ ngày 11/07/2020 giữa trường hợp đồng hóa (trái) và mặc định (phải), miền d03 (trên), miền d04 (dưới).

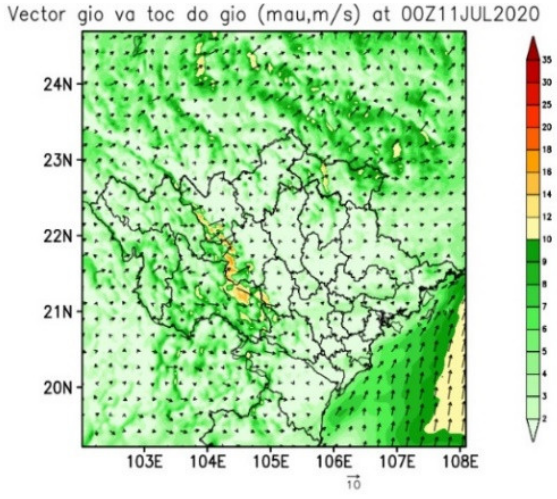

Vector gio va toc do gio $(\mathrm{mau}, \mathrm{m} / \mathrm{s})$ at 00Z11JUL2020

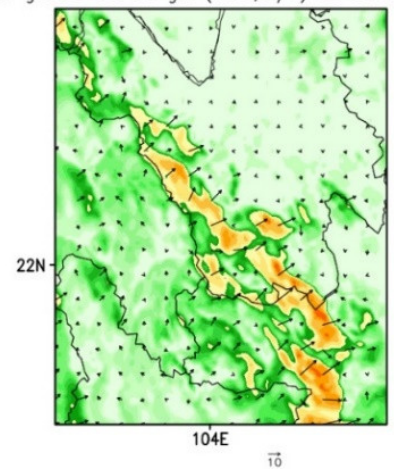

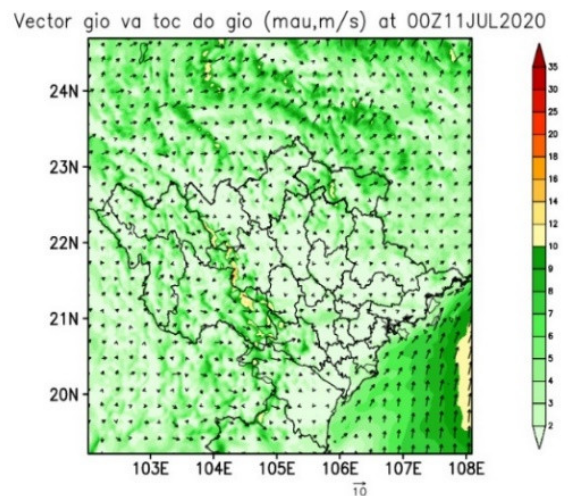

Vector gio va toc do gio (mau,m/s) at 00Z11JUL2020

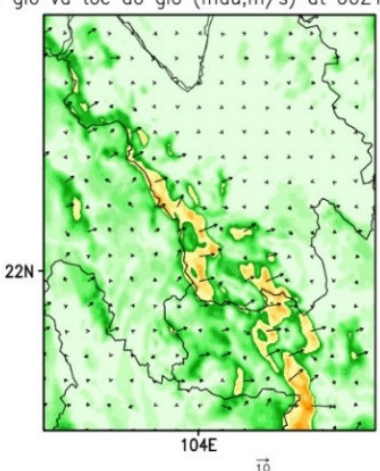

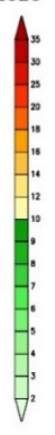

Hình 7. Bản đồ trường gió mực $10 \mathrm{~m}$ hạn dự báo 24 giờ thời điểm $00 \mathrm{Z}$ ngày $11 / 07 / 2020$ giữa trường hợp đồng hóa (trái) và mặc định (phải), miền d03 (trên), miền d04 (dưới). 


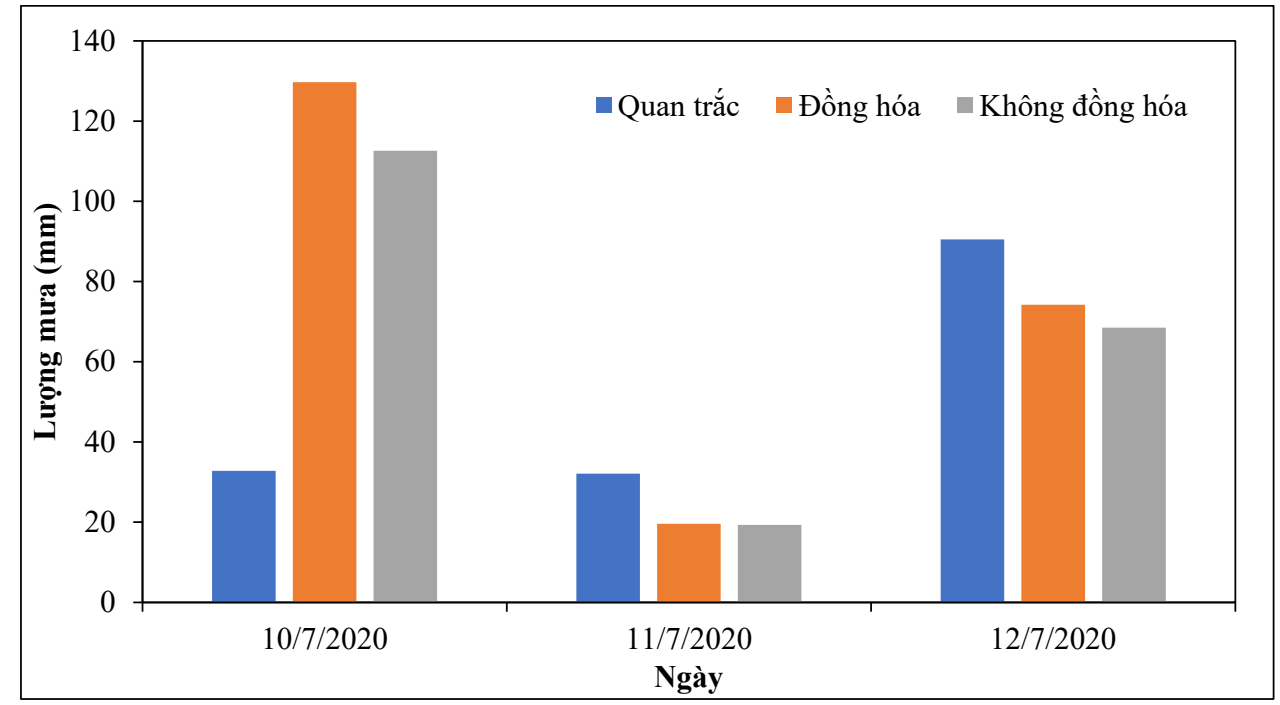

Hình 8. Biểu đồ so sánh lượng mưa giữa quan trắc và trường hợp đồng hóa, không đồng hóa.

Bảng 2. Kết quả so sánh giữa quan trắc và các trường hợp đồng hóa, không đồng hóa (mm).

\begin{tabular}{cccc}
\hline & $\mathbf{1 0 / 0 7 / 2 0 2 0}$ & $\mathbf{1 1 / 0 7 / 2 0 2 0}$ & $\mathbf{1 2 / 0 7 / 2 0 2 0}$ \\
\hline Quan trắc & 32,8 & 32,1 & 90,5 \\
Đồng hóa & 129,7 & 19,6 & 74,2 \\
Không đồng hóa & 112,6 & 19,3 & 68,5 \\
\hline
\end{tabular}

Biểu đồ Hình 8 thể hiện sự so sánh giữa lượng mưa quan trắc tại trạm Than Uyên và các trường hợp có đồng hóa, không đồng hóa. Kết quả cho thấy, ngày $10 / 7$, mô hình mô phỏng lượng mưa lớn hơn quan trắc, tuy nhiên ngày 11 và $12 / 7$ thì ngược lại. Giá trị chênh lệch ở ngày 11 và $12 / 7$ nhỏ hơn so với ngày $10 / 7$. So sánh lượng mưa mô phỏng giữa trường hợp đồng hóa và không đồng hóa cho thấy trường hợp có đồng hóa cho lượng mưa cao hơn.

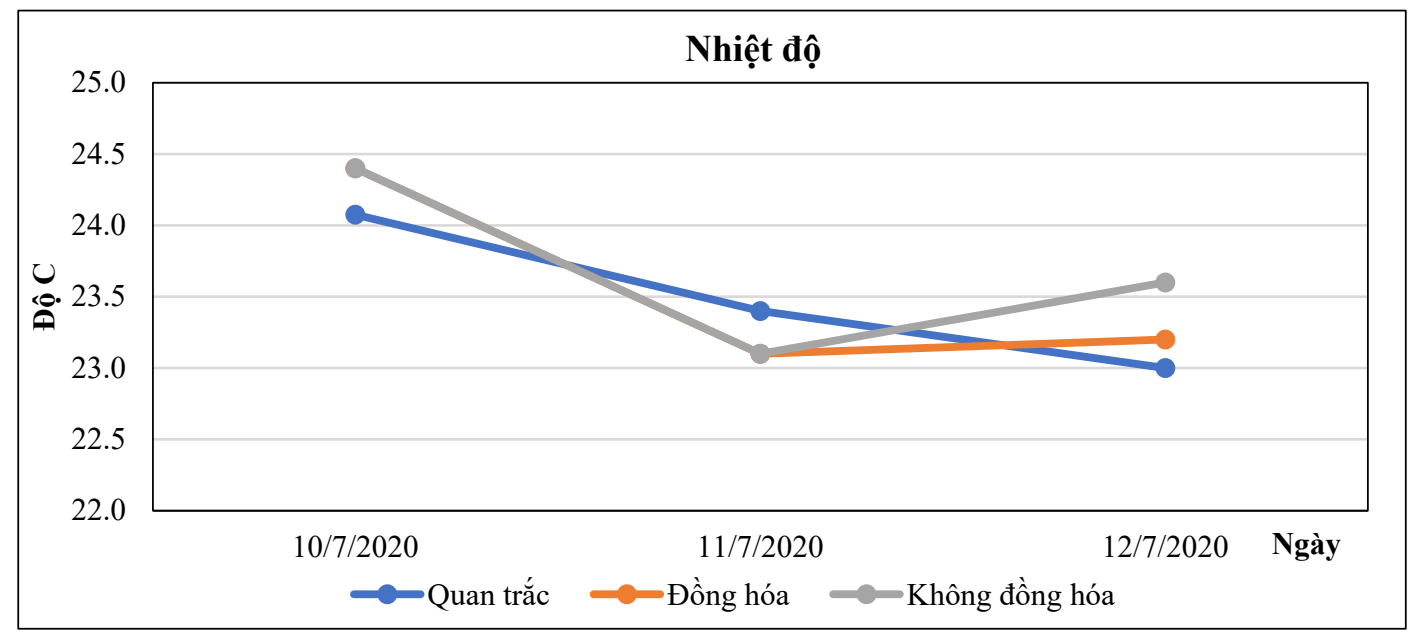

Hình 9. Biểu đồ so sánh nhiệt độ giữa quan trắc và các trường hợp đồng hóa, không đồng hóa.

Hình 9 là biểu đồ thể hiện sự so sánh về nhiệt độ giữa quan trắc và các trường hợp đồng hóa, không đồng hóa. Có thể thấy, trường hợp đồng hóa và không đồng hóa cho giá trị nhiệt độ tương đương nhau vào ngày 10 và 11/7/2020. Các giá trị này đều chênh lệch so với giá trị quan trắc khoảng 0,5 độ $\mathrm{C}$. Kết quả ngày $12 / 7$ có sự thay đổi khi giá trị nhiệt độ trường hợp đồng hóa gần với giá trị quan trắc hơn. Điều này cho thấy đồng hóa dữ liệu giúp cải thiện chất lượng dự báo nhiệt độ 3 ngày ở trường hợp này. 


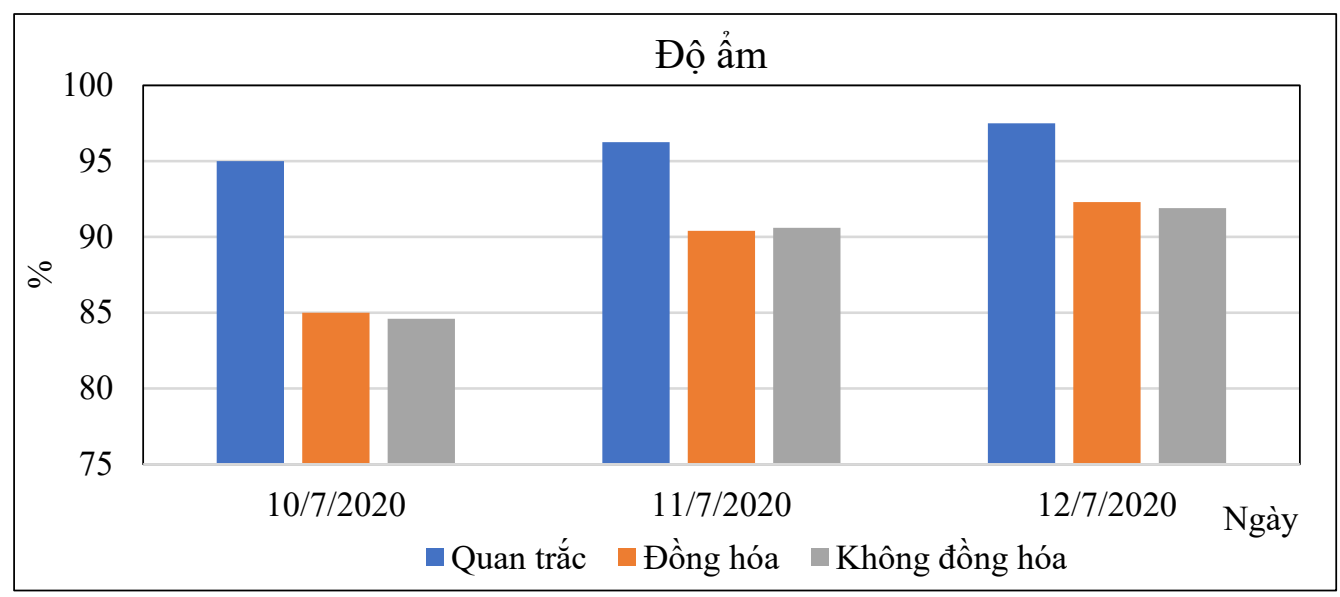

Hình 10. Biểu đồ so sánh độ ẩm giữa quan trắc và các trường hợp đồng hóa, không đồng hóa.

Kết quả so sánh độ ẩm tương đối giữa quan trắc và các trường hợp đồng hóa, không đồng hóa được thể hiện trong hình 10 . Kết quả cho thấy giá trị mô phỏng ở cả 2 trường hợp đồng hóa và không đồng hóa đều thấp hơn so với quan trắc. Độ ẩm tương đối ngày 10 và 12/7/2020 trường hợp đồng hóa cao hơn so với trường hợp không đồng hóa. Điều này cho thấy đồng hóa có cải thiện chất lượng dự báo trường độ ẩm nhưng không đáng kể.

Taylor Diagram

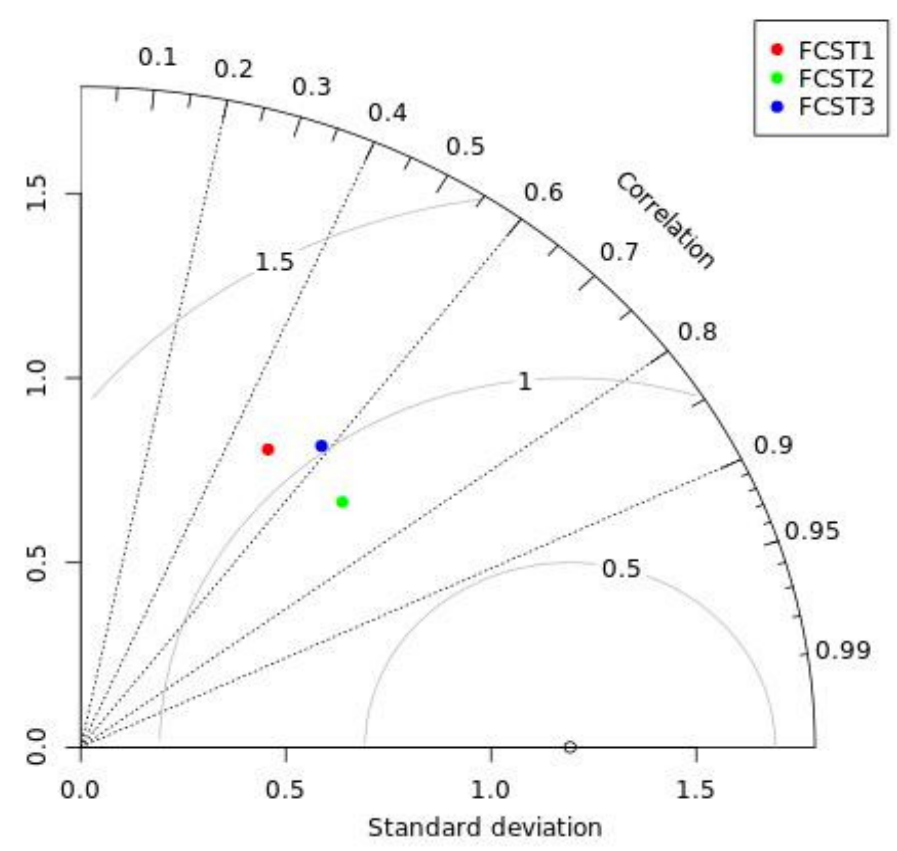

Hình 11. Giản đồ Taylor so sánh chất lượng các hạn dự báo: 1 ngày (đỏ), 2 ngày (xanh lá), 3 ngày (xanh dương).

Giản đồ Taylor (Hình 11) biểu thị so sánh chất lượng các hạn dự báo từ 1 đến 3 ngày, được tính toán dựa trên kết quả chạy dự báo 3 ngày cho các tháng 1 và tháng 7 . Có thể thấy, hạn dự báo 2 ngày (xanh lá) cho kết quả gần số liệu quan trắc nhất với chỉ số tương quan khoảng 0,7 . Hệ số tương quan của hạn dự báo 3 ngày (xanh dương) với quan trắc là 0,6 và của hạn dự báo 1 ngày (đỏ) là 0,5 . Như vậy, với hạn dự báo 1 ngày mô hình WRF cho kết quả dự báo kém hơn hạn 2 ngày và 3 ngày. Nguyên nhân có thể bởi mô hình cần có khoảng thời gian spin-up ban đầu nên khoảng thời gian này có thể làm ảnh hưởng đến chất lượng dự báo ngày thứ nhất. 


\section{Kết luận}

Nghiên cứu này sử dụng mô hình WRF để dự báo các trường khí tượng độ phân giải cao cho khu vực Than Uyên (Lai Châu) bằng phương pháp đồng hóa dữ liệu 3DVAR. Số liệu được sử dụng để đồng hóa bao gồm số liệu gió vệ tinh, số liệu quan trắc mặt đất và cao không. Mồ hình WRF với ba lưới lồng tương tác hai chiều, độ phân giải tương ứng là: $27 \mathrm{~km}, 9 \mathrm{~km}$, $3 \mathrm{~km}, 1 \mathrm{~km}$ thử nghiệm mô phỏng cho đợt mưa từ ngày 10-13 tháng 07 năm 2020 . Kết quả chất lượng dự báo về diện và lượng mưa ở trường hợp có đồng hóa số liệu đều được cải thiện hơn so với trường hợp không đồng hóa. Kêt quả dự báo các trường nhiệt độ, độ ậm, gió (bao gồm hướng gió và tốc gió) cũng được đánh giá. So sánh giữa quan trắc với trường hợp có đồng hóa, không đồng hóa cho thấy mô hình WRF có sử dụng kĩ thuật đồng hóa đã cải thiện được sai số dự báo ở các hạn dự báo song chất lượng cải thiện chưa cao. Tuy nhiên kết quả nghiên cứu cũng cho thấy tiềm năng của việc đồng hóa nhiều nguồn số liệu, sẽ giúp cải thiện tốt hơn trường ban đầu của mô hình khu vực, từ đó nâng cao chất lượng dự báo ở độ phân giải cao.

Đóng góp của tác giả: Xây dựng ý tưởng nghiên cứu: N.Đ.N., N.X.A, N.V.H.; Lựa chọn phương pháp nghiên cứu: N.X.A., N.V.H., N.Đ.N.; Thu thập, xử lý số liệu, chạy mô hình: N.Đ.N., N.T.M., N.T.L., P.L.K.; Viết bản thảo bài báo: N.Đ.N., N.T.M., N.V.H.; Chỉnh sửa bài báo: N.Đ.N., N.X.A., N.V.H.

Lời cảm ơn: Nghiên cứu này được thực hiện và hoàn thành nhờ sự hỗ trợ của Dự án: "Úng dụng công nghệ tự động hóa trong quá trình sản xuất nguyên liệu và quá trình sản xuất, chế biến chè xanh sao lăn chất lượng cao tại công ty cổ phần trà Than Uyên" Mã số: CNC 003/19 và Đề tài: "Nghiên cứu, thiết kế và chế tạo mẫu tên lửa nghiên cứu (Sounding Rocket) đưa thiết bị khoa học để thử nghiệm thu thập dữ liệu khí quyển tầng cao" Mã số: VT-CN.02/1820.

Lời cam đoan: Tập thể tác giả cam đoan bài báo này là công trình nghiên cứu của tập thể tác giả, chưa được công bố ở đâu, không được sao chép từ những nghiên cứu trước đây; không có sự tranh chấp lợi ích trong nhóm tác giả.

\section{Tài liệu tham khảo}

1. Huang, Y.; Liu, Y.; Li, H.; Knievel, J.C. Mechanisms for a Record-Breaking Rainfall in the Coastal Metropolitan City of Guangzhou, China: Observation Analysis and Nested Very Large Eddy Simulation With the WRF Model. J. Geophys. Res. Atmos. 2019, 124, 1370-1391.

2. Du, Y.; Rotunno, R. Diurnal Cycle of Rainfall and Winds near the South Coast of China. J. Atmos. Sci. 2018, 75, 2065-2082.

3. Ma, J.; Wang, H.; Fan, K. Dynamic Downscaling of Summer Precipitation Prediction over China in 1998 Using WRF and CCSM4. Adv. Atmos. Sci. 2015, 32, 577-584.

4. Hưng, M.K.; Tiến, D.D.; Sơn, L.V.; Hải, B.T.; Dung, P.T.P.; Quân, D.D. Đánh giá chất lượng dự báo mưa từ mô hình số trị cho khu vực Hà Nam và Nam Định trong năm 2019. Tap chí Khí tuợng Thủy văn 2020, 715, 37-48.

5. Lành, N.V.; Lam, N.T.T. Nghiên cứu mô phỏng và xác định cơ chế gây ra đợt mưa lớn vào đầu tháng 8 năm 2017 tại tỉnh Sơn La. Tạp chi Khí tuợng Thủy văn 2018, 692, 1-9.

6. Hường, C.T.T. Nghiên cứu thử nghiệm dự báo mưa thời hạn từ 1 đến 3 ngày cho khu vực Trung Bộ Việt Nam bằng mô hình WRF, Luận văn thạc sĩ, Trường ĐHKHTN, ĐHQGHN, 2007. 
7. Toàn, N.T. Dự báo mưa lớn do không khí lạnh kết hợp với dải hội tụ nhiệt đới từ 1 đến 3 ngày cho khu vực Trung Trung Bộ bằng mô hình WRF. Luận văn thạc sỹ, truòng ĐHKHTN-ĐHQGHN, 2011.

8. Tiến, D.Đ.; Tăng, B.M.; Hòa, V.V.; Vui, P.T.; Đức, T.A.; Hưng, M.K.; Linh, N.M. Đánh giá tác động của đồng hóa số liệu và điều kiện biên đến kết quả dự báo mưa lớn từ mô hình WRF cho khu vực tại miểnTrung và Tây Nguyên. Tạp chi Khí tượng Thủy văn 2014, 647, 25-30.

9. Tiến, T.T.; Thanh, T.N.T. Đồng hóa dữ liệu vệ tinh modis trong mô hình WRF để dự báo mưa lớn ở khu vực Trung Bộ. VNU J. Sci Nat. Sci. Technol. 2011, 27, 90-95.

10. Thanh, N.T. Nghiên cứu đồng hoá số liệu vệ tinh trong mô hình WRF để dự báo mưa lớn ở khu vực Trung Bộ, Luận văn thạc sĩ, Trường ĐHKHTN, ĐHQGHN, 2010.

11. Thăng, V.V. Thử nghiệm đồng hóa số liệu bằng WRF 4D-Var trong dự báo mưa ở khu vực Nam Bộ. Tạp chí Khí tượng Thủy văn 2019, EME2, 174-185. https://doi.org/10.36335/vnjhm.2019(eme2).174-185.

12. Thức, T.D; Thanh, C. Thử nghiệm đồng hóa dữ liệu radar trong mô hình WRF để dự báo mưa lớn cho khu vực Thành phố Hồ Chí Minh. VNU J. Sci Nat. Sci. Technol. 2018, 34(1S), 59-70.

13. Rostami, O.; Kashaninejad, N.; Moshksayan, K.; Saidi, M.S.; Firoozabadi, B.; Nguyen, N.T. Novel approaches in cancer management with circulating tumor cell clusters. J. Sci. Adv. Mater. Devices 2019, 4, 1-18.

14. Barker, D.M.; Huang, W.; Guo, Y.R.; Bourgeois, A.J.; Xiao, Q.N. A threedimensional ariational data assimilation system for $\mathrm{mm} 5$ : implementation and initial results. Mon. Weather Rev. 2004, 132, 897-914.

15. Courtier, P.; Thépaut, J.N.; Hollingsworth, A. A strategy for operational implementation of uppercase 4D-Var, using an incremental approach. Q. J.R. Meteor. Soc. 1994, 120, 1367-1387.

16. Ide, K.; Courtier, P.; Ghil, M.; Lorenc, A.C. Unified notation for data assimilation: operational, sequential and variational. J. Meteorol. Soc. Jpn. 1997, 75, 181-189.

17. Sugimoto, S.; Crook, N.A.; Sun, J.; Xiao, Q.; Barker, D.M. An examination of WRF 3DVAR radar data assimilation on its capability in retrieving unobserved variables and forecasting precipitation through observing system simulation experiments Mon. Weather Rev. 2009, 137, 4011-4029.

18. Parrish, D.F.; Derber, J.C. The national meteorological center's spectral statisticalinterpolation analysis system. Mon. Weather Rev. 1992, 120, 1747-1763.

19. Hương, T.T.M.; Hằng, N.T.; Tín, N.V.; Sơn, T.V.; Minh, P.T. Thử nghiệm đồng hóa số liệu gió vệ tinh và số liệu cao không để mô phỏng qũy đạo và cường độ cơn bão Haiyan 2013. Tạp chí Khí tương Thủy văn 2020, 716, 79-95. https://doi.org/10.36335/vnjhm.2020(716).79-95

20. Ngọc, L.A.; Tín, N.V.; Phát, T.N.; Hồng, N.V. Đánh giá khả năng dự báo thời tiết của mô hình WRF (Weather, Research and Forecasting) cho khu vực Nam Bộ. Tạp chi Khi tương Thủy văn 2019, 708, 55-63. https://doi.org/10.36335/vnjhm.2019(708).55-63. 
21. Thức, P.T. Ảnh hưởng của tham số bão tới nước dâng sau khi bão đổ bộ tại ven biển Bắc bộ. Tạp chi Khi tượng Thủy văn 2020, 712, 1-9. https://doi.org/10.36335/vnjhm.2020(712).1-9.

22. Tiến, D.Đ.; Cường, H.Đ.; Hưng, M.K.; Lâm, H.P. Đánh giá tác động của việc sử dụng tham số hóa đối lưu trong dự báo đợt mưa lớn tháng 7 năm 2015 trên khu vực Bắc Bộ bằng mô hình phân giải cao. Tạp chi Khí tương Thủy văn 2019, 1-8. https://doi.org/10.36335/VNJHM.2019(699).1-8.

\title{
Application of Data Assimilation for High-Resolution Simulation of Meteorological Variables over Than Uyen area (Lai Chau)
}

\author{
Nguyen Duc Nam ${ }^{1}$, Nguyen Tien Manh${ }^{1}$, Nguyen Thanh Linh ${ }^{1}$, Nguyen Xuan Anh ${ }^{1}$, \\ Pham Le Khuong ${ }^{1,3}$, Nguyen Van Hiep ${ }^{1,2^{*}}$ \\ ${ }^{1}$ Institute of Geophysics; ducnam.mi@gmail.com; ntmanh18196@gmail.com; \\ anhnx@igp-vast.vn; khuongpl@igp-vast.vn; nguyenthanhlinht58@gmail.com \\ ${ }^{2}$ Northern Delta Regional Hydro-Meteorological Center; hiepwork@gmail.com \\ ${ }^{3}$ Graduate University of Science and Technology; khuongpl@igp-vast.vn
}

\begin{abstract}
In this research, the WRF model with a 3DVAR data assimilation is used to simulate the high-resolution meteorological fields for Than Uyen (Lai Chau) area. The data used include satellite wind data, surface observations at stations and sounding data within the model domains. The results showed that data assimilation improved the quality forecast of temperature, humidity and precipitation in comparison with the control case.
\end{abstract}

Keywords: WRF3DVAR; Data assimilation; Spin-up; Heavy Rainfall. 